\title{
Cariprazine as a Treatment Option for Depressive Episodes Associated with Bipolar I Disorder in Adults: An Evidence-Based Review of Recent Data
}

\author{
Mauricio Tohen \\ Department of Psychiatry and Behavioral \\ Sciences, University of New Mexico, \\ Albuquerque, NM, USA
}

\begin{abstract}
Depressive episodes, the most frequent episodes in bipolar disorder, contribute in large part to poor functional outcomes. Very few treatments, however, have been approved by the Food and Drug Administration for the treatment of bipolar depression. Cariprazine, a broad-spectrum dopamine antagonist/partial agonist with dopamine D3/D2 (preferring D3) and serotonin 5-HT1A receptor partial agonist properties, was recently approved. A review of the literature suggests that it is an effective and well-tolerated treatment for bipolar depression.
\end{abstract}

Keywords: Cariprazine, bipolar depression, antipsychotics, psychopharmacology

\section{Introduction}

Bipolar disorder is a long-term recurrent psychiatric condition characterized by episodes of mania, depression, and hypomania interspersed with symptom-free periods. ${ }^{1}$ Blanco et al. ${ }^{2}$ found in a US representative sample that for bipolar disorder the one-year prevalence in adults was $1.5 \%$ and the lifetime prevalence was $2.1 \%$. Bipolar disorder is associated with medical and substance use disorder ${ }^{3}$ comorbidities which result in poor functional outcomes, ${ }^{4}$ poor quality of life, and premature mortality. $^{2}$

Several predictors of poor outcomes in bipolar disorder have been identified, ${ }^{5}$ including young age of onset, ${ }^{6}$ duration of untreated mania, ${ }^{7}$ comorbidities, ${ }^{8-10}$ presence of psychotic features, ${ }^{11}$ and presence of depressive symptoms. ${ }^{9,12}$

Depressive episodes are the most prevalent episodes in bipolar disorder. Studies have shown that depressive episodes occur three times more often than manic episodes. ${ }^{13}$ Also, depressive episodes are the most common initial presentation, estimated to be in $50-80 \%$ of cases of this disorder. ${ }^{14}$ Longitudinal studies have found that $70 \%$ of the time spent unwell is with the presence of depressive symptoms. ${ }^{1}$ Depressive episodes and persistent subsyndromal depressive symptoms often lead to poor quality of life and high risk of suicide. ${ }^{1}$ Studies also have found that patients with bipolar depression with a history of predominant lifetime depressive episodes, in general, have poor response to treatment. ${ }^{15}$

The misdiagnosis of bipolar depression is common, as many as $60 \%$ of patients are misdiagnosed with major depressive disorder when a history of past manic, or hypomanic episode is not documented. ${ }^{1}$ Misdiagnosis leads to the use of antidepressants which are not effective in bipolar depression and in some cases may
Department of Psychiatry and Behavioral Sciences, University of New Mexico, 2400

Tucker Ave NE, MSC09 5030,

Albuquerque, NM, 87I3।, USA

Email mtohen@salud.unm.edu 
induce mania or rapid cycling. ${ }^{16}$ Accurate diagnosis is imperative for a wide range of providers including psychiatrists, psychiatric nurse practitioners, and primary care providers. Effective early treatment is of paramount importance; data has shown better outcomes if intervention is early and both psychosocial $^{7}$ and pharmacological. ${ }^{17}$

For bipolar depression, the identification of predictors of response to specific pharmacological treatment has been shown to be of value. ${ }^{18}$ Mixed features in bipolar disorder can present in a variety of clinical presentations (eg, mania with depression, mania with subsyndromal depression, or hypomania with depression).

Most patients with mania also experience depression with different degrees of severity and number of depressive symptoms ${ }^{19}$ which cause functional dysfunction. ${ }^{9}$ The presence of depressive symptoms in mania has been found to be a predictor of relapse into depression, ${ }^{9}$ including in first-episode patients. ${ }^{10,20}$ After remission, patients continue to have subsyndromal symptoms. Depressive symptoms are the most prevalent, cause more disability, ${ }^{21}$ and increase the likelihood of relapse into depression. ${ }^{12}$

The Food and Drug Administration (FDA) has approved several medications for the treatment of manic episodes associated with bipolar I disorder, including second generation antipsychotics, lithium, and valproate. Fewer treatments have been approved for bipolar depression. The first treatment approved by any regulatory agency worldwide was the olanzapine/fluoxetine combination in $2009^{22}$ by the FDA, followed by quetiapine (immediate-and extended-release) in $2013,{ }^{23}$ lurasidone in $2017,{ }^{24}$ and most recently cariprazine in $2019 .^{25}$ However, only two monotherapy treatments, quetiapine and cariprazine, have FDA approval for the acute treatment of both mania and depression. Olanzapine monotherapy has shown efficacy in bipolar depression ${ }^{18,26,27}$ but has not been approved by the FDA. Not all atypical antipsychotics have shown efficacy in treating bipolar depression; examples include ziprasidone ${ }^{28}$ and aripiprazole. $^{29}$

Cariprazine is a broad-spectrum dopamine antagonist/ partial agonist (DAPA) with dopamine D3/D2 (preferring D3) and serotonin 5-HT1A receptor partial agonist properties. It has FDA approval for the treatment of schizophrenia $(1.5-6 \mathrm{mg} / \mathrm{d})$, acute manic/mixed episodes (3-6 mg/d), and depressive episodes associated with bipolar disorder depression (1.5-3mg/day). ${ }^{30,31}$ In the European Union, it has only been approved for schizophrenia.

\section{Pharmaco-Dynamic Studies in Humans}

Cariprazine has been found in PET ligand studies to have preferential binding to dopamine D3 over D2 receptors in patients with schizophrenia. ${ }^{32}$ Studies have suggested that D3 receptors play a role in the regulation of motivation and reward-related behavior. Investigators have concluded that cariprazine is a D3-preferring dual D3/D2 receptor partial agonist. ${ }^{32}$ Of note, diagnostic task-specific activations in functional MRI, a novel technique developed by Stoyanov et al. ${ }^{33}$ has been shown to help in the diagnosis of psychotic conditions but has not been studied with the use of cariprazine in patients with bipolar depression.

\section{Efficacy in Bipolar Depression}

The FDA approved cariprazine for the treatment of bipolar depression in 2019 based on the results of three randomized, double-blind, placebo-controlled trials: RGH-MD -56 [NCT01396447], ${ }^{34}$ RGH-MD-54 [NCT02670551], ${ }^{35}$ and RGH-MD-53 [NCT026705382020]. ${ }^{36}$

All three studies have a similar design with a screening and no-drug washout period of up to 14 days, followed by double-blind treatment, and a one-week safety follow-up. The double-blind period was eight weeks in RGH-MD-56, and six weeks in RGH-MD-53, and in RGH-MD-54. The endpoint was at week six in all studies.

These studies were conducted in the US and 12 other countries. Participants were 18-65 years old with a diagnosis of bipolar depression without psychotic features of at least four weeks but no more than 12 weeks duration. The following criteria were followed in all studies: Minimum score of 20 in the Hamilton Depression Rating Scale ${ }^{37}$ with Item 1 scored at 2 or higher; Clinical Global Impression-Severity ${ }^{38}$ of 4 or higher; and Young Mania rating scale ${ }^{39}$ of 10 or less in MD-56, and 12 or less for MD-53 and MD-54. In the latter two studies, participants had to be outpatients. Exclusion criteria included risk of suicide as determined by the Columbia-Suicide Severity Rating Scale ${ }^{40}$ or a history of substance dependence in the last six months.

The first published study on cariprazine in bipolar depression was RGH-MD-56 [NCT01396447]. ${ }^{34}$ It was an eight-week randomized, double-blind, placebocontrolled, parallel-group, fixed-dose study in adult patients with bipolar depression. Patients were randomly assigned (1:1:1:1) to receive placebo or cariprazine at $0.75,1.5$, or $3.0 \mathrm{mg} /$ day. The primary outcome was change 
from baseline to week six on the Montgomery-Åsberg Depression Rating Scale (MADRS). ${ }^{41}$

Cariprazine at $1.5 \mathrm{mg}$ /day showed significantly greater improvement on MADRS total score from baseline to week six compared with placebo. Cariprazine at $3.0 \mathrm{mg} /$ day showed greater MADRS score reduction than the placebo but was not significant when adjusted for multiple comparisons. The $0.75 \mathrm{mg} /$ day dosage results were similar to the placebo. The most common adverse events (AEs) $(\geq 10 \%)$ in cariprazine-treated patients were akathisia and insomnia; weight gain was slightly higher with cariprazine than with the placebo.

The authors concluded that cariprazine at $1.5 \mathrm{mg}$ /day in the treatment of bipolar depression demonstrated consistent efficacy compared with placebo across outcomes and the dosage was generally well tolerated.

The second published study was RGH-MD-54 [NCT02670551], ${ }^{35}$ a double-blind, placebo-controlled study for the treatment of bipolar depression. Patients were randomly assigned to receive placebo, or cariprazine $1.5 \mathrm{mg} /$ day or $3.0 \mathrm{mg} /$ day.

Both dosages of cariprazine were significantly more effective than the placebo in improving depressive symptoms (reducing MADRS total score); common treatment-emergent adverse events (TEAEs) (in at least $5 \%$ of participants in either cariprazine-treatment group and twice the rate of the placebo group) were nausea, akathisia, dizziness, and sedation. Mean changes in weight and metabolic parameters were relatively small and comparable across groups.

The third study, RGH-MD-53 [NCT02670538], ${ }^{36}$ was a Phase 3 double-blind, placebo-controlled study. Patients were randomized to placebo, cariprazine $1.5 \mathrm{mg}$ /day, or cariprazine $3.0 \mathrm{mg} /$ day. Efficacy parameters were identified as changes in the MADRS total scores from baseline to week six compared to placebo. Cariprazine $1.5 \mathrm{mg} /$ day significantly reduced depressive symptoms on the MADRS score efficacy parameters versus placebo, however, differences were not statistically significant for cariprazine $3.0 \mathrm{mg} /$ day. Common treatment-emergent adverse events were akathisia, restlessness, nausea, and fatigue. Mean metabolic parameter changes were low and generally comparable among groups; mean weight increases were $\leq 0.5 \mathrm{~kg}$ for all groups.

\section{Pooled Data}

Yatham et $\mathrm{al}^{42}$ pooled data from these three similarly designed randomized, double-blind, placebo-controlled studies of adults with bipolar depression comparing cariprazine with placebo. ${ }^{34-36}$ MADRS total scores and individual item scores mean change, from baseline to week six, were analyzed in dose groups of $1.5 \mathrm{mg} / \mathrm{d}$, $3 \mathrm{mg} / \mathrm{d}$, and $1.5-3 \mathrm{mg} / \mathrm{d}$ combined. A statistically significant greater difference in mean change from baseline in MADRS total score was seen for each cariprazine dose group versus the placebo. In addition, significant $(P<$ $0.05)$ differences versus placebo were seen on all individual MADRS items except inner tension for the overall cariprazine group. The authors concluded that cariprazine showed efficacy across most symptoms in bipolar depression.

\section{Pooled Subgroup Analysis}

Patel et $\mathrm{al}^{43}$ recently conducted post hoc analyses on the three randomized, double-blind, placebo-controlled trials in bipolar I depression (NCT01396447, NCT02670538 and NCT02670551) that evaluated the same primary outcome consisting of mean change from baseline in MADRS total scores for pooled cariprazine $1.5-3 \mathrm{mg} / \mathrm{d}$ versus placebo. They also conducted secondary analysis based on demographic and clinical characteristics.

The mean difference in MADRS total score change from baseline was statistically significant for cariprazine $1.5-3 \mathrm{mg} / \mathrm{d}$ versus placebo in all patient subgroups including age, gender, race, BMI level, as well as course of illness characteristics.

Cariprazine $1.5-3 \mathrm{mg} / \mathrm{d}$ improved depressive symptoms in all patient subgroups including baseline demographic and clinical characteristics.

\section{Bipolar Depression with Mixed Features}

McIntyre et $\mathrm{al}^{44}$ conducted post hoc analysis and found that cariprazine at both doses of 1.5 or $3 \mathrm{mg}$ were statistically significantly effective in patients with bipolar depression and manic features. However, for those without manic features only the $1.5 \mathrm{mg}$ dosage showed a statistically significant difference.

\section{Efficacy in Functional Outcomes}

Depressive symptoms are associated with poor functional outcome in bipolar disorder, other variables include longer duration of illness, psychotic features, older age, number of previous episodes, number of previous hospitalizations, and comorbid substance use disorder. ${ }^{8,9,21,45-47}$ There is no clear consensus definition for poor psychosocial 
functioning; therefore, it is important to consider different behavioral outcomes such as social function, occupational function, ability to live independently, and capacity for recreation. $^{48}$

As mentioned before, cariprazine is a broad-spectrum dopamine antagonist/partial agonist with dopamine D3/D2 (preferring D3) and serotonin 5-HT1A receptor partial agonist. $^{32}$ D3 receptors are associated with regulation of motivation and reward-related behavior. However, to date, the measurement in change in functional impairment in patients with bipolar depression has not been studied.

Studies recently focused on the efficacy of cariprazine on psychosocial function in patients with bipolar depression without psychotic features. ${ }^{49,50}$ The authors conducted a post hoc analysis on a randomized, doubleblind, placebo-controlled parallel-group, fixed-dose study. $^{34}$ The study was eight weeks of double-blind treatment randomized $(1: 1: 1: 1)$ to placebo or cariprazine, $0.75 \mathrm{mg} / \mathrm{d}, 1.5 \mathrm{mg} / \mathrm{d}$, or $3.0 \mathrm{mg} / \mathrm{d}$. Analyses were conducted in mean changes from baseline to week eight in the Functional Assessment Short Test (FAST) ${ }^{47}$ total and subscale scores.

Statistically significant differences were noted for cariprazine $1.5 \mathrm{mg} / \mathrm{d}$ compared to placebo in mean change from baseline in FAST total score and on five of six subscale scores; cariprazine $3 \mathrm{mg} / \mathrm{d}$ was significantly different on the Interpersonal Relationship subscale. Rates of functional remission and recovery, and $\geq 30 \%$ or $\geq 50 \%$ improvement from baseline, were significantly greater for cariprazine 1.5 versus placebo; the percentage of patients with $\geq 30 \%$ improvement was also significantly different for cariprazine $3 \mathrm{mg} / \mathrm{d}$ versus placebo. The authors concluded that cariprazine could be beneficial for patients with bipolar depression with functional deficits. Importantly, functional improvement was more robust for $1.5 \mathrm{mg} / \mathrm{d}$ dose than for the $3 \mathrm{mg} / \mathrm{d}$ dose.

\section{Long Term Exploratory Efficacy and Safety}

Ketter et al evaluated the safety and tolerability of cariprazine in a 16-week open label study in patients with mania who had responded to cariprazine. ${ }^{51}$ The mean treatment duration was 58 days; cariprazine was administered with flexible dosing (3-12) $\mathrm{mg}$ with average dose of $6.2 \mathrm{mg} /$ day in 402 adults ages $18-65$. Completion rate was $33 \%$. Efficacy was measured with the Young Mania Rating
Scale (YMRS). The average total score decreased 15.2 points at week 16 .

The most frequent reasons for discontinuation were withdrawal of consent (20\%), protocol violation (14\%), and adverse events $(16 \%)$. The most common adverse events that led to discontinuation were akathisia (4.7\%) and depression (1.5\%). Serious adverse events were present in $7.5 \%$ of participants. The most common adverse events were mania [2.2\%] and depression [1.2\%]; 83.3\% had treatmentemergent AEs, including akathisia (32.6\%), headache (16.7\%), constipation (10.7\%), and nausea (10.4\%). 9.3\% had $\geq 7 \%$ weight gain; $5.7 \%$ had sedation; $3 \%$ had somnolence. No clinically significant mean changes in laboratory values, vital signs, or ECGs were reported.

\section{Safety and Tolerability}

Earley et $\mathrm{al}^{52}$ evaluated the safety and tolerability of cariprazine compared to placebo. The investigators pooled four randomized, double-blind, placebo-controlled trials in patients with bipolar depression. ${ }^{34-36}$

Nausea and akathisia were the only TEAEs that occurred in more than $5 \%$ of patients in the overall cariprazine group, and at twice the rate of placebo. Nausea was present in $8 \%$ of patients receiving cariprazine and $3 \%$ in patients receiving the placebo. Akathisia was present in $7 \%$ of patients receiving cariprazine and $2 \%$ in patients receiving the placebo. Metabolic changes were small and relatively similar for cariprazine and placebo; mean increase in glucose was $3.1 \mathrm{mg} / \mathrm{dL}$ for cariprazine and $2.6 \mathrm{mg} / \mathrm{dL}$ for placebo.

Cariprazine-treated patients and placebo-treated patients showed similar differences in mean changes from baseline to the end of study in cardiac and ECG parameters. In addition, similar changes were found in the two modal-dose groups analysis. No patients had a QTcB interval $>500 \mathrm{msec}$ and one patient in the $1.5 \mathrm{mg}$ fixed-dose group had a QTcF interval >500 $\mathrm{msec}$. Suicidal ideation was reported in $1.2 \%$ of cariprazinetreated patients and $1.3 \%$ of placebo-treated patients. There was no weight gain of more than one $\mathrm{kg}$ in any group. Treatment-emergent akathisia occurred in $9.9 \%$ of cariprazine and in $4.3 \%$ placebo-treated patients. Of note, there was a potential dose response relationship with $6.1 \%$ in cariprazine $<1.5 \mathrm{mg}, 8.5 \%$ with $1.5 \mathrm{mg}$, and $13.8 \%$ with $3 \mathrm{mg}$. Treatment-emergent parkinsonism occurred in $2.1 \%$ in cariprazine treated-patients and $0.4 \%$ of placebo-treated patients, with no clear dose response observed $<1.5 \mathrm{mg}=$ $2.2 \%, 1.5 \mathrm{mg}=1.1 \%, 3 \mathrm{mg}=3.5 \%$. 
Discontinuation rate due to any cause was $22.1 \%$ for cariprazine-treated patients and $20.2 \%$ of placebo-treated patients. No adverse event led to discontinuation in more than $2 \%$ of cases. Akathisia was the most common adverse event leading to discontinuation $(1.1 \%)$ in the cariprazine group compared to $0 \%$ in the placebo group. Fixed-dose and modal-dose findings were generally consistent. However, metabolic changes in the fixed-dose were higher in the $3 \mathrm{mg}$ compared to the $1.5 \mathrm{mg}$ group.

The authors point out comparison of adverse events in studies of cariprazine in the treatment of mania with apparently better tolerability in patients treated with bipolar depression. ${ }^{52}$ Importantly in the mania studies a higher dose of cariprazine $(3-12 \mathrm{mg} / \mathrm{d})$ was utilized. Patients received cariprazine at a starting dose of $1.5 \mathrm{mg} / \mathrm{d}$ on day 1 , with an increase to $3.0 \mathrm{mg} / \mathrm{d}$ on day $2 .{ }^{53}$ Extra pyramidal symptoms (EPS) had lower rates in bipolar depression compared with mania studies. Favorable rates were seen in patients receiving cariprazine for bipolar depression compared to mania including EPS-related TEAEs excluding akathisia/restlessness ( $5 \%$ vs $28 \%$ ), akathisia ( $7 \%$ vs $20 \%$ ), and EPS-related discontinuations (excluding akathisia/restlessness $=0.3 \%$ vs $1 \%$; akathisia $=1 \%$ vs $2 \%$ ). This suggests a potential dose-response relationship in EPS-related events in both bipolar depression and mania.

\section{Concomitant Use of Cariprazine with Other Medications}

To date, there are no published studies addressing, in a systematic way, the efficacy or tolerability of cariprazine in combination with other psychotropic agents.

\section{Special Populations Child and Adolescents}

The safety and tolerability of cariprazine has been studied in pediatric patients with schizophrenia and bipolar disorder. Cariprazine was studied in an open-label, 4-week, multicenter Phase I clinical study in pediatric patients, between the age of 13 and 18, with schizophrenia (EudraCT Number: 2016-002327-29). The goal of the study was to assess the pharmacokinetics, safety, and tolerability of cariprazine in adolescents. Efficacy was not studied in this trial. Three groups of patients were selected: $13-15$ years $(n=22), 15-18$ years $(n=21)$, and $18-40$ years $(n=20)$; all groups were studied for up to 48 weeks. Patients were randomized to either cariprazine or risperidone. After a fix dose period of 2-4 weeks, patients were followed for up to 48 weeks. Dosing was flexible on the respective treatment arm with $1.5-9 \mathrm{mg} /$ day $(1.5 \mathrm{mg}$, $3 \mathrm{mg}, 6 \mathrm{mg}$, or $9 \mathrm{mg}$ ) for cariprazine or $2-12 \mathrm{mg} /$ day $(2 \mathrm{mg}$, $4 \mathrm{mg}, 6 \mathrm{mg}, 8 \mathrm{mg}, 10 \mathrm{mg}$, or $12 \mathrm{mg}$ ) for risperidone.

For the cariprazine group no deaths or serious adverse events were reported. More TEAEs and study drug-related TEAEs were reported for age group 15-18 than for age groups $13-15$ and 18-40. The number of patients who reported AEs in 13-15-year-olds and 18-40-year-olds were similar. No clear trend with dose in the number of TEAEs or study drug-related TEAEs was observed. In the 13-15-year-old group, the most frequent TEAE (occurring in $\geq 5 \%$ of patients) was sedation in $13.6 \%$.

In the opinion of the investigators, all TEAEs were of mild or moderate intensity with the exception of one case in age group 15-18, who had headache and tonsillitis of severe intensity.

In age-group 15-18, the most frequent TEAEs (occurring in $\geq 5)$ were akathisia and somnolence in five $(23.8 \%)$ patients, tension headache in four $(19.0 \%)$ patients, nausea in three (14.3\%) patients, and dizziness postural, sedation, fatigue, abnormal dreams, sleep disorder, and hypotension in two $(9.5 \%)$ patients.

In all groups, effects on clinical laboratory, vital signs, and ECGs were small and not clinically meaningful. The investigators report no treatment emergent Parkinsonism, with akathisia being recorded only in the age group 15-18. The investigators did not report direct comparisons between the risperidone and the cariprazine groups other than study discontinuations, which favored risperidone with $66.7 \%$ completion rate compared to $37.3 \%$ for the cariprazine group. The investigators concluded that in 13-18-year olds, cariprazine was generally well tolerated in the 4-week study, without serious adverse events. Adverse events in adolescents were similar to those in the adult population. There was no clear trend in the number of TEAEs in the 13-15 age group compared to the 15-18 age group, nor increased dose-related incidence of TEAEs. The majority of documented TEAEs were mild to moderate intensity. Akathisia was only present in the 15-18-year olds. No clinically significant differences were documented in clinical laboratory, vital sign, or ECG measures.

Another report on the safety and tolerability of cariprazine in pediatric patients with schizophrenia and bipolar disorder found that the safety findings in this study were consistent with the known safety profile of cariprazine in 
adults. There were no deaths, SAEs, discontinuations due to AE, and no reported suicidal ideations or suicidal behaviors in the study. There were no differences in safety observations by titration schedule, except transient initial decreased blood pressure observed in those with faster titration.

There were no clinically meaningful differences in the number, or severity, of the reported TEAEs among age groups. The most frequently reported treatment-related TEAEs $(\geq 2)$ were parkinsonism, sedation, tremor, dystonia, and blurred vision. Eleven patients had a weight increase of $\geq 7 \%$ from baseline to endpoint. Mean increases in weight over the course of the study reflected normal growth patterns for children and adolescents. Few laboratory values shifted from normal at baseline to low or high at endpoint. Metabolic parameters (glucose, total cholesterol, and triglycerides), prolactin levels, and white blood cell function parameters were generally within normal limits. No participant had a postbaseline ECG change in $\mathrm{QTc}>60$ seconds.

\section{Elderly}

The efficacy, safety, and tolerability of cariprazine were examined in patients with schizophrenia ages 65-74 in a 48-week, open-label trial (ClinicalTrials.gov. NCT01625897, study A002-A7). Patients were randomized to cariprazine $(n=17)$ or risperidone $(n=10)$. In the cariprazine group $16 / 17$ (94.1\%) patients and 10/10 $(100 \%)$ in the risperidone group experienced at least one TEAE. Four patients in the cariprazine group and 1 in the risperidone group experienced at least one serious adverse event. There were more discontinuations in the cariprazine $(52 \%)$ than in the risperidone $(20.0 \%)$ group. The most common side effects in the cariprazine group were psychosis, nasopharyngitis, insomnia, hypertension, and weight gain. In the risperidone group, the most common side effects were hyperprolactinemia, insomnia, and parkinsonism. For the cariprazine group, with the exception of glucose levels, clinical laboratory changes were not significant. For glucose, the mean baseline of $104.9 \mathrm{mg} / \mathrm{dl}$ increased on average $20.8 \mathrm{mg} / \mathrm{dl}$ at study end. Prolactin levels increased in the risperidone group on average from 23.6 at baseline to $62.5 \mathrm{ng} / \mathrm{mL}$ at endpoint. Vital signs and ECG changes were not clinically significant except for one patient in the cariprazine group with a QTcF of $501 \mathrm{~ms}$ in one visit only. Parkinsonism was experienced by $40 \%$ of the risperidone-treated patients and $17.6 \%$ in the cariprazine group. No treatment-emergent akathisia was reported in either group. The authors concluded that there are no differences in the safety and tolerability of cariprazine across different age groups.

In summary, cariprazine in the treatment of patients with bipolar depression without psychotic features appears to be effective and have a generally favorable safety and tolerability profile in $1.5 \mathrm{mg} / \mathrm{d}$ and $3 \mathrm{mg} / \mathrm{d}$ doses. In general, efficacy appears to be best in the $1.5 \mathrm{mg}$ dose. Tolerability also appears to be dose related. In the fixed-dose analysis, tolerability was slightly better in the $1.5 \mathrm{mg} / \mathrm{d}$ group than in the $3 \mathrm{mg} / \mathrm{d}$ group. As more data becomes available, meta-analysis and secondary analyses no doubt will help the field better understand the advantages and limitations of cariprazine in the treatment of bipolar depression.

\section{Acknowledgments}

The author would like to thank Cameron Colbert-Olivas and Pari Noskin for their editorial review efforts.

\section{Disclosure}

Dr Tohen reports being a paid consultant from AbbVie, during the writing of this article and has been a paid consultant for AstraZeneca, Abbott, AbbVie, BMS, Lilly, GSK, J\&J, Otsuka, Roche, Lundbeck, Elan, Alkermes, Allergan, Intracellular Therapies, Merck, Minerva, Neurocrine, Pamlab, Alexza, Forest, Teva, Sunovion, and Gedeon Richter. Dr Tohen was a full-time employee at Lilly (1997 to 2008).

\section{References}

1. Baldessarini RJ, Vieta E, Calabrese JR, Tohen M, Bowden CL. Bipolar depression: overview and commentary. Harv Rev Psychiatry. 2010;18 (3):143-157. doi:10.3109/10673221003747955

2. Blanco C, Compton WM, Saha TD, et al. Epidemiology of DSM-5 bipolar I disorder: results from the National Epidemiologic Survey on Alcohol and Related Conditions - III. $J$ Psychiatr Res. 2017;84:310-317. doi:10.1016/j.jpsychires.2016.10.003

3. Tohen M, Greenfield SF, Weiss RD, Zarate CA, Vagge LM. The effect of comorbid substance use disorders on the course of bipolar disorder: a review. Harv Rev Psychiatry. 1998;6(3):133-141. doi:10.3109/ 10673229809000321

4. Tohen M, Hennen J, Zarate CM, et al. Two-year syndromal and functional recovery in 219 cases of first-episode major affective disorder with psychotic features. Am J Psychiatry. 2000;157(2):220-228. doi:10.1176/appi.ajp.157.2.220

5. Treuer T, Tohen M. Predicting the course and outcome of bipolar disorder: a review. Eur Psychiatry. 2010;25(6):328-333. doi:10.1016/ j.eurpsy.2009.11.012

6. Tohen M, Strakowski SM, Zarate C, et al. The McLean-Harvard first-episode project: 6-month symptomatic and functional outcome in affective and nonaffective psychosis. Biol Psychiatry. 2000;48 (6):467-476. doi:10.1016/s0006-3223(00)00915-x 
7. Vieta E, Salagre E, Grande I, et al. Early intervention in bipolar disorder. Am J Psychiatry. 2018;175(5):411-426. doi:10.1176/appi. ajp.2017.17090972

8. Dion GL, Tohen M, Anthony WA, Waternaux CS. Symptoms and functioning of patients with bipolar disorder six months after hospitalization. Hosp Community Psychiatry. 1988;39(6):652-657. doi:10.1176/ps.39.6.652

9. Tohen M, Waternaux CM, Tsuang MT. Outcome in mania. A 4-year prospective follow-up of 75 patients utilizing survival analysis. Arch Gen Psychiatry. 1990;47(12):1106-1111. doi:10.1001/ archpsyc. 1990.01810240026005

10. Tohen M, Waternaux CM, Tsuang MT, Hunt AT. Four-year follow-up of twenty-four first-episode manic patients. J Affect Disord. 1990;19 (2):79-86. doi:10.1016/0165-0327(90)90012-w

11. Tohen M, Tsuang MT, Goodwin DC. Prediction of outcome in mania by mood-congruent or mood-incongruent psychotic features. $\mathrm{Am}$ J Psychiatry. 1992;149(11):1580-1584. doi:10.1176/ajp.149.11.1580

12. Tohen M, Bowden CL, Calabrese JR, et al. Influence of sub-syndromal symptoms after remission from manic or mixed episodes. $\mathrm{Br}$ J Psychiatry. 2006;189:515-519. doi:10.1192/bjp.bp.105.020321

13. Judd LL, Akiskal HS, Schettler PJ, et al. The long-term natural history of the weekly symptomatic status of bipolar I disorder. Arch Gen Psychiatry. 2002;59(6):530-537. doi:10.1001/archpsyc.59.6.530

14. O’Donovan C, Alda M. Depression preceding diagnosis of bipolar disorder. Front Psychiatry. 2020;11:500. doi:10.3389/fpsyt.2020.00500

15. Vieta E, Berk M, Wang W, Colom F, Tohen M, Baldessarini RJ. Predominant previous polarity as an outcome predictor in a controlled treatment trial for depression in bipolar I disorder patients. J Affect Disord. 2009;119(1-3):22-27. doi:10.1016/j. jad.2009.02.028

16. Pacchiarotti I, Bond DJ, Baldessarini RJ, et al. The International Society for Bipolar Disorders (ISBD) task force report on antidepressant use in bipolar disorders. Am J Psychiatry. 2013;170 (11):1249-1262. doi:10.1176/appi.ajp.2013.13020185

17. Ketter TA, Houston JP, Adams DH, et al. Differential efficacy of olanzapine and lithium in preventing manic or mixed recurrence in patients with bipolar I disorder based on number of previous manic or mixed episodes. J Clin Psychiatry. 2006;67(1):95-101. doi:10.4088/ jcp.v67n0113

18. Tohen M, Katagiri H, Fujikoshi S, Kanba S. Efficacy of olanzapine monotherapy in acute bipolar depression: a pooled analysis of controlled studies. J Affect Disord. 2013;149(1-3):196-201. doi:10.1016/ j.jad.2013.01.022

19. Tohen M, Gold AK, Sylvia LG, et al. Bipolar mixed features Results from the comparative effectiveness for bipolar disorder (Bipolar CHOICE) study [published correction appears in $\mathrm{J}$ Affect Disord. 2018 Jan 1;225:775-777]. J Affect Disord. 2017;217:183-189. doi:10.1016/j.jad.2017.03.070

20. Tohen M, Zarate CA, Hennen J, et al. The McLean-Harvard First-Episode Mania Study: prediction of recovery and first recurrence. Am J Psychiatry. 2003;160(12):2099-2107. doi:10.1176/ appi.ajp.160.12.2099

21. Gitlin MJ, Mintz J, Sokolski K, Hammen C, Altshuler LL. Subsyndromal depressive symptoms after symptomatic recovery from mania are associated with delayed functional recovery. J Clin Psychiatry. 2011;72(5):692-697. doi:10.4088/JCP.09m05291gre

22. Zyprexa (olanzapine). Package Insert. Eli Lilly and Company; 2009.

23. Sertoquel XR (quetiapine fuarate extended-release). Package Insert. AstraZenca Pharmaceutical LP; 2013.

24. Latuda (lurasione HCL) tablets. Package Insert. Sunovion Pharmaceutical; 2017.

25. VRAYLAR (cariprazine). Package Insert. Allergan plc; 2019.
26. Tohen M, Vieta E, Calabrese J, et al. Efficacy of olanzapine and olanzapine-fluoxetine combination in the treatment of bipolar I depression [published correction appears in Arch Gen Psychiatry. 2004 Feb;61(2):176]. Arch Gen Psychiatry. 2003;60(11):1079-1088. doi:10.1001/archpsyc.60.11.1079

27. Tohen M, McDonnell DP, Case M, et al. Randomised, double-blind, placebo-controlled study of olanzapine in patients with bipolar I depression. Br J Psychiatry. 2012;201(5):376-382. doi:10.1192/bjp. bp. 112.108357

28. Lombardo I, Sachs G, Kolluri S, Kremer C, Yang R. Two 6-week, randomized, double-blind, placebo-controlled studies of ziprasidone in outpatients with bipolar I depression: did baseline characteristics impact trial outcome? J Clin Psychopharmacol. 2012;32(4):470-478. doi:10.1097/JCP.0b013e31825ccde5

29. Thase ME, Bowden CL, Nashat M, et al. Aripiprazole in bipolar depression: a pooled, post-hoc analysis by severity of core depressive symptoms. Int J Psychiatry Clin Pract. 2012;16(2):121-131. doi:10.3109/13651501.2011.632680

30. Cho DI, Zheng M, Kim KM. Current perspectives on the selective regulation of dopamine $\mathrm{D}_{2}$ and $\mathrm{D}_{3}$ receptors. Arch Pharm Res. 2010;33(10):1521-1538. doi:10.1007/s12272-010-1005-8

31. Tohen M. Cariprazine in bipolar disorders. J Clin Psychiatry. 2015;76 (3):e368-e370. doi:10.4088/JCP.14com09606

32. Girgis RR, Slifstein M, D'Souza D, et al. Preferential binding to dopamine D3 over D2 receptors by cariprazine in patients with schizophrenia using PET with the D3/D2 receptor ligand [(11)C]-(+)PHNO. Psychopharmacology (Berl). 2016;233(19-20):3503-3512. doi:10.1007/s00213-016-4382-y

33. Stoyanov D, Aryutova K, Kandilarova S, et al. Diagnostic task specific activations in functional MRI and aberrant connectivity of insula with middle frontal gyrus can inform the differential diagnosis of psychosis. Diagnostics (Basel). 2021;11(1):95. doi:10.3390/ diagnostics 11010095

34. Durgam S, Earley W, Lipschitz A, et al. An 8-week randomized, double-blind, placebo-controlled evaluation of the safety and efficacy of cariprazine in patients with bipolar I depression. Am J Psychiatry. 2016;173(3):271-281. doi:10.1176/appi.ajp.2015.15020164

35. Earley W, Burgess MV, Rekeda L, et al. Cariprazine treatment of bipolar depression: a randomized double-blind placebo-controlled phase 3 study. Am J Psychiatry. 2019;176(6):439-448. doi:10.1176/ appi.ajp.2018.18070824

36. Earley WR, Burgess MV, Khan B, et al. Efficacy and safety of cariprazine in bipolar I depression: a double-blind, placebo-controlled phase 3 study. Bipolar Disord. 2020;22 (4):372-384. doi:10.1111/bdi.12852

37. Hamilton M. A rating scale for depression. J Neurol Neurosurg Psychiatry. 1960;23(1):56-62. doi:10.1136/jnnp.23.1.56

38. Guy W; National Institute of Mental Health (U.S.). Psychopharmacology research branch, early clinical drug evaluation program. In: Ecdeu Assessment Manual for Psychopharmacology. Rev. Rockville, Md.: U.S. Dept. of Health, Education, and Welfare, Public Health Service, Alcohol, Drug Abuse, and Mental Health Administration, National Institute of Mental Health, Psychopharmacology Research Branch, Division of Extramural Research Programs; 1976.

39. Young RC, Biggs JT, Ziegler VE, Meyer DA. A rating scale for mania: reliability, validity and sensitivity. $\mathrm{Br} J$ Psychiatry. 1978;133:429-435. doi:10.1192/bjp.133.5.429

40. Posner K, Brown GK, Stanley B, et al. The Columbia-Suicide Severity Rating Scale: initial validity and internal consistency findings from three multisite studies with adolescents and adults. Am $J \quad$ Psychiatry. 2011;168(12):1266-1277. doi:10.1176/appi. ajp.2011.10111704 
41. Montgomery SA, Åsberg M. A new depression scale designed to be sensitive to change. Br J Psychiatry. 1979;134:382-389. doi:10.1192/ bjp.134.4.382

42. Yatham LN, Vieta E, McIntyre RS, Jain R, Patel M, Earley W. Broad efficacy of cariprazine on depressive symptoms in bipolar disorder and the clinical implications. Prim Care Companion CNS Disord. 2020;22(5):20m02611. doi:10.4088/PCC.20m02611

43. Patel M, Jain R, Tohen M, Maletic V, Earley WR, Yatham LN. Efficacy of cariprazine in bipolar I depression across patient characteristics: a post hoc analysis of pooled randomized, placebo-controlled studies. Int Clin Psychopharmacol. 2021;36 (2):76-83. doi:10.1097/YIC.0000000000000344

44. McIntyre RS, Masand PS, Earley W, Patel M. Cariprazine for the treatment of bipolar mania with mixed features: a post hoc pooled analysis of 3 trials. J Affect Disord. 2019;257:600-606. doi:10.1016/j. jad.2019.07.020

45. Kapczinski NS, Narvaez JC, Magalhães PV, et al. Cognition and functioning in bipolar depression [published correction appears in Rev Bras Psiquiatr. 2016 Jul-Sep;38(3):266]. Braz J Psychiatry. 2016;38(3):201-206. doi:10.1590/1516-4446-2014-1558

46. Bonnín CM, Martínez-Arán A, Torrent C, et al. Clinical and neurocognitive predictors of functional outcome in bipolar euthymic patients: a long-term, follow-up study. J Affect Disord. 2010;121(1-2):156-160. doi:10.1016/j.jad.2009.05.014

47. Rosa AR, Sánchez-Moreno J, Martínez-Aran A, et al. Validity and reliability of the Functioning Assessment Short Test (FAST) in bipolar disorder. Clin Pract Epidemiol Ment Health. 2007;3:5. doi:10.1186/1745-0179-3-5

48. Zarate CA, Tohen M, Land M, Cavanagh S. Functional impairment and cognition in bipolar disorder. Psychiatr Q. 2000;71(4):309-329. doi:10.1023/a:1004632206684
49. Patel MD, Vieta E, Calabrese J, Whelan J, Tohen M. Efficacy of cariprazine on functioning in patients with bipolar depression: post hoc analysis of a randomized, placebo-controlled trial. Poster to be presented at: American Psychiatric Association Annual Meeting; May 2021; virtual.

50. Vieta E, Calabrese JR, Whelan J, Tohen M, Earley W. The efficacy of cariprazine on function in patients with bipolar depression: a post hoc analysis of a randomized controlled trial. Curr Med Res Opin. 2021.

51. Ketter TA, Sachs GS, Durgam S, et al. The safety and tolerability of cariprazine in patients with manic or mixed episodes associated with bipolar I disorder: a 16-week open-label study. J Affect Disord. 2018;225:350-356. doi:10.1016/j.jad.2017.08.040

52. Earley WR, Burgess M, Rekeda L, et al. A pooled post hoc analysis evaluating the safety and tolerability of cariprazine in bipolar depression. $J$ Affect Disord. 2020;263:386-395. doi:10.1016/j. jad.2019.11.098

53. Calabrese JR, Keck, Jr PE, Starace A, et al. Efficacy and safety of low- and high-dose cariprazine in acute and mixed mania associated with bipolar I disorder: a double-blind, placebo-controlled study. J Clin Psychiatry. 2015;76(3):284-292. doi:10.4088/JCP.14m09081

54. Szatmári B, Barabássy Á, Harsányi J, et al. Cariprazine safety in adolescents and the elderly: analyses of clinical study data. Front Psychiatry. 2020;11:61. doi:10.3389/fpsyt.2020.00061

55. Riccobene T, Riesenberg R, Yeung P, Earley W, Hankinson A, Periclou A. Pharmacokinetics and safety/tolerability profile of cariprazine in pediatric patients with schizophrenia or bipolar I disorder. Presented at: 67th American Academy of Child and Adolescent Psychiatry Annual Meeting; October 19-24, 2020; virtual.

\section{Publish your work in this journal}

Drug Design, Development and Therapy is an international, peerreviewed open-access journal that spans the spectrum of drug design and development through to clinical applications. Clinical outcomes, patient safety, and programs for the development and effective, safe, and sustained use of medicines are a feature of the journal, which has also been accepted for indexing on PubMed Central. The manuscript management system is completely online and includes a very quick and fair peer-review system, which is all easy to use. Visit http://www. dovepress.com/testimonials.php to read real quotes from published authors. 